\title{
HISTÓRIA E MEMÓRIA NA CONSTRUÇÃO DO PENSAMENTO HISTÓRICO: UMA INVESTIGAÇÃO EM EDUCAÇÃO HISTÓRICA
}

\author{
Prof ${ }^{\mathrm{a}}$. Dr ${ }^{\mathrm{a}}$ Marlene Rosa Cainelli \\ Universidade Estadual de Londrina \\ cainelli@uel.br \\ Prof $^{a}$.Dr ${ }^{a}$. Magda Madalena P. Tuma \\ Universidade Estadual de Londrina \\ mtuma@uel.br ${ }^{1}$
}

\begin{abstract}
RESUMO:
O projeto em desenvolvimento: Iniciando crianças na arte do conhecimento histórico, parte do pressuposto que crianças assimilam representações da realidade que adquirem na família, na sociedade, na mídia o que resulta em suportes para o desenvolvimento do pensamento histórico. O objetivo desta pesquisa é discutir sobre o processo de ensino e aprendizagem na perspectiva da educação histórica na tentativa de perceber quais relações estabelecem as crianças com a ciência da História e com os procedimentos de construção do conhecimento histórico em sala de aula. É uma pesquisa empírica que busca além da observação de campo, a interferência no processo de ensino aprendizagem. O objeto escolhido para este artigo é um trabalho de campo realizado com alunos da $4^{\mathrm{a}}$ série no "Memorial do Pioneiro" recentemente inaugurado na cidade de Londrina.

Palavras -chave: educação histórica, ensino de história, memória.

\section{HISTORY AND MEMORY IN THE CONSTRUCTION OF HISTORICAL THOUGHT: AN HISTORICAL RESEARCH IN EDUCATION}

\begin{abstract}
:
The underway project "Introducing children into the art of knowing History" is based on the assumption that children assimilate representations of reality they learn from family, society, and the media, which act as supports for the development of their historical thought. The objective of this study is to discuss the teaching and learning process from the history education perspective, in an attempt to find out the relationships children establish with the science of History and with the procedures of history knowledge construction in the classroom. It is an empirical research that aims not only at field observation but also at interfering in the process of teaching and learning. The subjects of this study were $4^{\text {th }}$ grade students who participated in a field study carried out at "Memorial do Pioneiro" , a historical site recently inaugurated in the city of Londrina.
\end{abstract}

Key words: History Education, History teaching, memory 
"O estudo do passado não é um guia seguro para predizer o futuro. Porém, ele nos prepara para o futuro, expandindo nossa experiência, fazendo com que possamos aumentar nossas habilidades, nossa energia - e se tudo for bem, nossa sabedoria"'.

... "Mas só sabemos essas coisas sobre o futuro porque estudamos o passado: sem isso não teríamos nem mesmo o conhecimento dessas verdades fundamentais, não saberíamos as palavras para expressá-las, ou até quem, ou onde, ou o que nós somos. Só conhecemos o futuro através do passado nele projetado. Nesse sentido a História é tudo que temos.” Jonh Lewis Gaddis

Segundo, Ivo Mattozzi (1998:24) devemos tomar consciência de que a "história ensinada nas escolas para crianças e adolescentes pode não ter qualquer eficácia , ou a sua eficácia pode ser contrariada pelas contra-histórias que circulam fora da escola". No projeto de Pesquisa que desenvolvemos acreditamos que a escola pode interferir nestas "contra-histórias" tomando como suporte metodológico para ensinar história o desenvolvimento das capacidades cognitivas das crianças para pensar historicamente.

Mattozzi (1998) afirma ainda que a escola deveria formar personalidades cognitivas capazes de submeter a exame a lógica das construções dos discursos sobre o passado. Seria partir do desenvolvimento das estruturas de pensamento sobre o mundo de uma perspectiva histórica que possibilitaríamos aos alunos, desde as séries iniciais, uma formação histórica que fugisse da formação conteudista dos currículos. Este pensar historicamente está intimamente relacionado com a complexidade da temporalidade histórica. Como afirma Siman (2003, p.119)

Pensar historicamente supõe a capacidade de identificar e explicar permanências e rupturas entre o presente/passado e futuro, a capacidade de relacionar os acontecimentos e seus estruturantes de longa e média duração em seus ritmos diferenciados de mudança; capacidade de identificar simultaneidade de acontecimentos no tempo cronológico; capacidade de relacionar diferentes dimensões da vida social em contextos sociais diferentes. Supõe identificar, no próprio cotidiano, nas relações sociais, nas ações políticas da atualidade, a continuidade de elementos do passado, reforçando o diálogo passado/presente.

As estruturas de pensamento, que a criança precisa para aprender história, para Lee (2001), está intimamente relacionada com a capacidade de estabelecer inferências e analisar evidências. $\mathrm{O}$ trabalho do professor deve ancorar-se nos passos realizados pelo historiador para escrever sobre o passado. É preciso construir juntamente com a criança os meios para que ela entenda os procedimentos da construção historiográfica e como o historiador analisa os vestígios nos documentos para escrever a história. Nesse sentido, enfatizar o trabalho do historiador como método norteador das atividades na aula de história.

Ensinar a criança a observar, analisar e identificar a História estudada como uma construção humana permite que ela entenda a provisoriedade do conhecimento histórico, identificando-o como produto da investigação histórica. É necessário que o professor 
perceba que a leitura do mundo onde se vive o tempo presente, é o maior laboratório de estudo para a aprendizagem em história.

Apresentaremos neste texto um trabalho de campo realizado na cidade de Londrina com crianças da quarta série do ensino fundamental em torno da inauguração do Memorial do Pioneiro. O Memorial é uma construção em uma praça da cidade conhecida como Concha Acústica, esta compõe se de 17 totens com a inscrição dos nomes dos primeiros colonizadores da cidade, denominados de pioneiros. O caráter de "pioneiro" para constar no Memorial foi atribuído àqueles que chegaram na cidade de 21/08/1929 a 31/12/1939. São em torno de 3800 nomes gravados em ordem alfabética nos totens espalhados pela praça. Os nomes destes foram retirados do cadastro ${ }^{2}$ de pioneiros criados pelo Museu Histórico de Londrina, Padre Carlos Weiss. Dois Totens que compõem o memorial não possuem nomes, sendo um dedicado aos indígenas e, outro, aos desbravadores. julho de 2007

Vista parcial do Memorial do Pioneiro na Praça da Concha Acústica. Londrina- Paraná-Brasil -

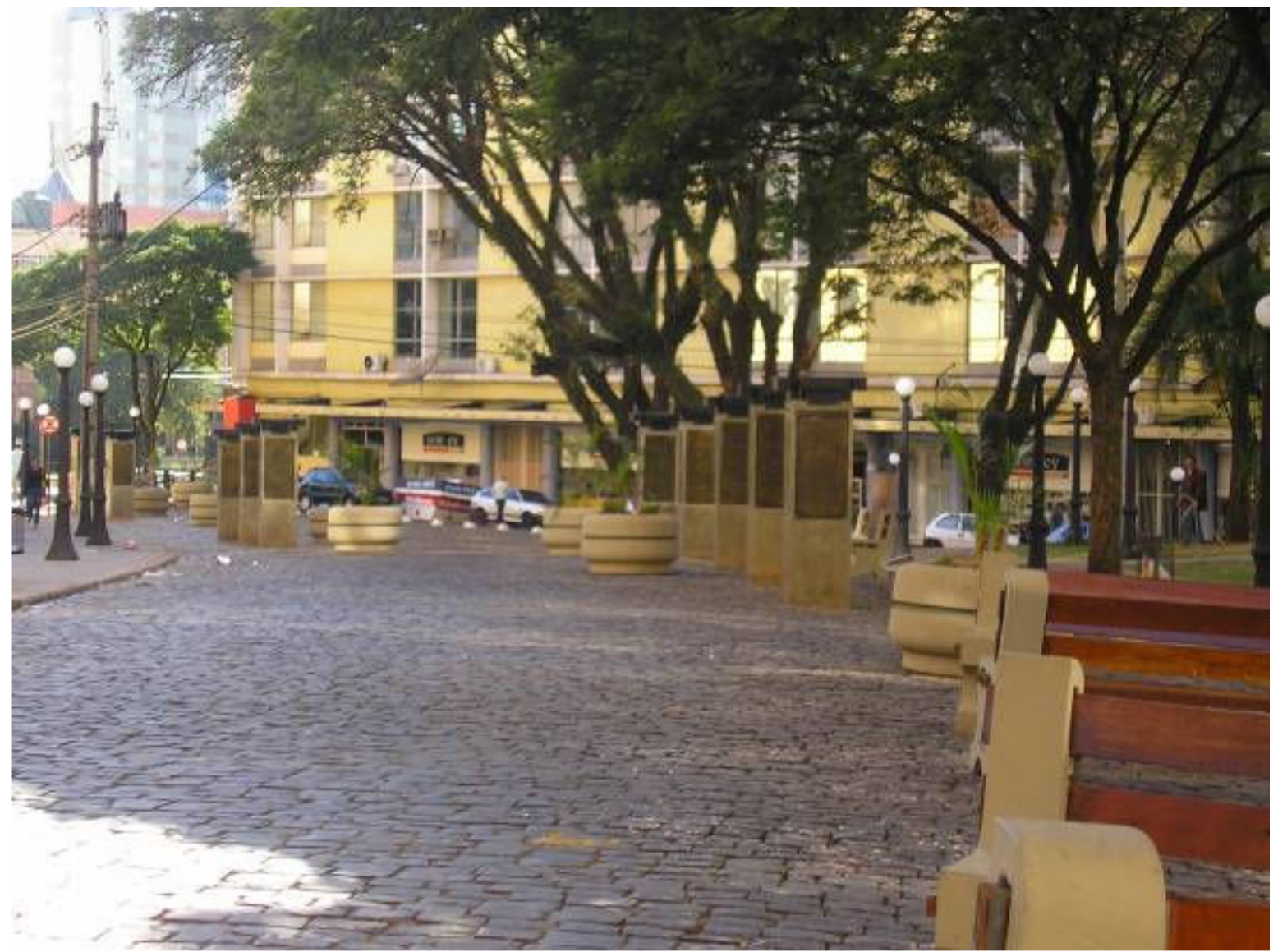

Foto: Marlene Cainelli (2007)

A Concha Acústica ${ }^{3}$ enquanto espaço de memória na cidade de Londrina, estaria, em nosso entendimento, vinculado ao anonimato dos trabalhadores em suas festas de $1^{\circ}$ de maio. O poder público ao utilizar-se do local para instalar o Memorial do Pioneiro, 
renomeou este espaço, impondo nomes e monumentos, deslocando o foco da memória dos trabalhadores anônimos para o dos colonizadores, representados pela figura do pioneiro. De acordo com Arruda (2005:1) estes locais, como o Memorial, seriam como "semióforos" criados com a única finalidade de serem expostos ao olhar, articulando o visível e o invisível, o passado e o presente. Entendemos a idéia de "semióforo" como a possibilidade de representar e perpetuar o invisível do passado, representado pelos nomes dos pioneiros.

É importante mencionar, para o entendimento dos significados que atribuímos a instalação do Memorial na Concha Acústica, que a mesma é um "ponto de referência” já consagrado pela população como espaço de 'monumento'. Ela já se encontra inserida como diria Pierre Nora (1984), como 'lugar da memória' no imaginário local, pois está em região central, portanto, com visibilidade dada pela configuração espacial que lembra a ágora, ao sugerir a condição de espaço para encontros, debates, manifestações etc. Assim, não se trata de um lugar qualquer, mas sim daquele que está presente no cotidiano de trajetórias de vidas, relembrando a vinculação ao passado e fortalecendo a necessidade de pertencimento. É um monumento que já tem a condição estabelecida de mediador entre a memória individual e a coletiva, ao propiciar o contato entre a primeira, a do Eu com a dos 'Outros' e materializar parte da base comum de vida, além de revelar esforços para o enraizamento de 'determinada memória'. A construção do memorial nos sugere ações que buscam superar a presença da memória dos 'anônimos' em termos de espaço arquitetônico dedicado à expressão popular para a inserção do instituído, datado, nomeado.

Em contraposição ao existente, o Memorial, não se destacará por seu aspecto arquitetônico, e sim pela forma que dá visibilidade aos atores da fundação do município, ou seja, pela inscrição dos nomes, o que de certa forma, resgataria a estratégia de permanência que já se difundia na memória litúrgica da Idade Média na França. Mesmo sendo oral e para cerimônias, segundo Geary (2006:171), aquela estratégia buscava a potencialidade do texto para a transmissão e deslocamento pelo espaço da memória afirmada e veiculada pela inscrição de nomes em rolos mortuários, que garantiria a presença espiritual mesmo que não fossem lidos. É a memória escrita, colocada para a evocação do passado, não só na esfera religiosa como também na sociedade cristã laica, para a presença na rememoração que permanece no século XXI.

Esta discussão ainda impõe a problemática da memória em regiões de colonização recente como o caso de Londrina que foi elevada à condição de município em 1934. A aparente perda de uma história/memória da cidade juntamente com o desaparecimento dos colonizadores, desencadeia uma discussão em torno da memória/história a ser perpetuada e da criação dos "lugares de memória" no qual, as gerações presentes e futuras, podem e poderão ver como teria sido o início/fundação do município.

Nesse sentido, concordamos com Nora (1985)... "fala se tanto de memória porque ela não existe mais". Como seria possível mediar um diálogo com algo que não existe mais? Este vazio que Nora atribui ao fim das "sociedades - memória [que] seria preenchido pelas memórias históricas. A memória assim só sobreviveria no campo da história e nos lugares destinados a ela, não mais espontânea e coletivamente. Ao edificar no centro da cidade um monumento aos "pioneiros", o poder público ergue um semióforo fundamental, aquele que será irradiador do poder conforme Chauí (2001). Como não existiria um passado a se remeter visto que a ação dos pioneiros ainda agoniza nos suportes da memória, o ato de ter participado, ter estado presente, ter dado continuidade ao ato de fundação ganha status de poder e prestígio. (Arruda, 2005) .

No caso do Memorial do Pioneiro trabalharemos aqui com a idéia do memorial como um monumento seguindo o conceito de Le Goff (1985:95) 
(...) o monumentum é um sinal do passado. Atendendo suas origens filológicas, o monumento é tudo aquilo que pode evocar o passado, perpetuar a recordação, por exemplo, os atos escritos.(...) O monumento tem como característica o ligar-se ao poder de perpetuação, voluntária ou involuntária, das sociedades históricas( é um legado a memória coletiva) e o reenviar a testemunhos que só uma parcela mínima são testemunhos escritos.

Para nós o monumento Memorial do Pioneiro representa um documento, é testemunho de uma época, mas testemunho que pretende perpetuar uma visão, uma interpretação, uma memória.

\section{Crianças, nomes e monumentos: construindo o pensamento histórico}

No primeiro contato com a produção de dez crianças, que compareceram na escola, após a visita ao Memorial na Concha Acústica, nos chamou atenção a observação que a maioria fez em relação aos totens nos quais constam apenas as inscrições "desbravadores" e 'indígenas', os alunos ao se referirem a eles atribuíram a ausência de nomes a condição de 'não importância' no processo colonizador, e ressaltaram a permanência da mística em torno do nome como materialização da importância de pessoas nesse processo, associada à irrelevância atribuída aos sujeitos históricos sem nome como 'massa de anônimos'.

Encontrar em crianças, cujas idades variam entre 9-11 anos, tal valorização do nome como presença histórica, nos remeteu ao processo de construção da memória que se estabeleceu em Londrina, a partir da década de 1950, e expressivamente no ano de 1959, por ocasião da comemoração dos 25 anos do município, quando um conjunto de realizações aconteceu por meio da edição de Álbum sobre as famílias pioneiras; edição do livro "Londrina 25 anos de sua História"; eleição de Rainha, Criação de um Mural de Azulejos e baile de gala; oficialização dos Hinos e em obras como a do Lago Igapó. A Concha Acústica pertence ao rol dessa década.

A memória não tem sua existência baseada apenas em comemorações, conforme indica Geary (2006), em tempo anterior, como na Europa medieval ela já emergia em variadas acepções e dimensões das ações humanas, superando a subjetividade da religião e inserindo se no profano em inúmeros sentidos. O que nos interessa é que Geary aponta a memória social como processo "que permite à sociedade renovar e reformar sua compreensão do passado a fim de integrá-lo em sua identidade presente" (2006:167), envolvendo variadas dimensões presentes na historiografia, tradição oral e outras formas de produção e reprodução cultural.

Sem a pretensão de revisitar todas as perspectivas teóricas abertas pela colocação da 'memória' em evidência, propusemos atividades às crianças relacionadas à memória por meio do monumento, que teve o Memorial do Pioneiro, tomado como documento, por entendermos aqui que a perspectiva de nossa proposta envolve o documento como fonte $\mathrm{e}$ como recurso didático para o ensino de história. A principal atividade didática consistiu na observação das crianças diante do monumento e do pensamento que elaboraram perante a presença de dezessete totens, sendo um deles dedicado aos desbravadores e o outro aos indígenas.

Antes da saída escola até o Memorial as crianças responderam quatro perguntas em sala de aula, sobre o que conheciam a respeito de alguns conceitos como: pioneiro; monumento; memorial do pioneiro e sobre o que sabiam sobre história de Londrina. Após este trabalho, nos encaminhamos ao Memorial do Pioneiro onde propusemos que 
observassem os totens verificando o que ofereciam como informação sobre a História de Londrina. Permanecemos no local em torno de duas horas, em período no qual as crianças se aproximaram do conteúdo (nomes e datas) inscritos nos totens e realizaram desenhos representando os totens de forma livre. Apenas acompanhávamos suas descobertas e/ou respondíamos às questões que propunham. As professoras da turma acompanharam todo o trabalho e este momento pareceu despertar o interesse de todos.

No trabalho de campo constatamos na prática o que para Pollack (1989) deve ser considerado como trazer à visibilidade 'memórias subterrâneas', que ao demonstrar sua sobrevivência, traz também, a possibilidade de múltiplas reivindicações. Isto aconteceu no memorial no momento do trabalho com as crianças ao sermos inquiridas por um homem reclamando da condição de filho de pioneiro e pioneiro ausente do Memorial, portanto, confinados à condição anônima.

Não era a oposição entre poder público e população que emergiria naquele ato isolado, o que nos chamou atenção foi a necessidade de buscar vias para a manutenção do EU com os OUTROS, que permanece nas lembranças individuais e apareceu na reivindicação da presença na coletividade. A inserção no coletivo era o que reivindicava aquele senhor, entendendo que a visibilidade do nome garantiria este lugar. O Memorial também representaria o que já começa a se configurar como espaço do fim do silêncio em relação às agruras e glórias do ser pioneiro. São sentimentos ambivalentes que originam a presença de 3800 nomes que possivelmente serão ampliados, pois a condição de anônimo(s) é o que trará à tona as disputas, os ressentimentos e as razões políticas que entendem como excludentes, na manifestação em contexto ruidoso do desejo de compartilhar.

O trabalho com a memória através da visita ao Memorial com as crianças visou reconhecer que as reflexões das crianças sobre elementos da História como monumento, pioneiro, totem, desbravadores e indígenas são construções pessoais, mas nem por isso desvinculadas da rede de interdependência na qual nos constituímos conforme Elias (1994), ao estar impregnada do conhecimento cotidiano. Em relação à História, Carretero (1997) tem apontado a dificuldade da compreensão dos conceitos históricos e a desconsideração deste aspecto em trabalhos desenvolvidos com crianças e jovens no ensino de História, o que ainda em muitos aspectos permanece nebuloso pela atenção restrita que se dá aos saberes construídos previamente pelas crianças nas diversas dimensões do convívio sociocultural.

Quando Vygotsky (ano)afirma a condição de mediação que cabe ao professor, ele remete à necessidade de se estabelecer conexões entre o que se pretende ensinar e o que a criança já sabe, para o enfrentamento das resistências manifestadas pelas crianças, ao terem construído sobre estes saberes prévios sua própria lógica, podendo desta maneira se configurar como barreira à aceitação do redimensionamento do conceito.

Nossa intervenção pretende possibilitar a construção do pensamento histórico através da relação entre os conhecimentos prévios e os conhecimentos históricos. Importante salientar que a mediação do professor é fundamental nesta trajetória, é ele quem estabelece as relações. Segundo Siman, "as ações mediadoras incidem sobre os processos cognitivos de apropriação de novos conceitos de modos de raciocinar em história, quanto a respeito das possibilidades reais e potenciais dos alunos pensarem historicamente". (Siman, 2004:90)

Comparando a escrita das crianças antes e depois da visita ao memorial percebemos, assim como afirma Mattozzi (1998:30) "que a história ensinada deve ter em primeiro lugar uma função cognitiva de formação das estruturas mentais dos alunos". Dessa forma iniciando pelo conceito de pioneiro, o aluno Fernando os define como Revista HISTEDBR On-line, Campinas, n.34, p.211-222, jun.2009 - ISSN: 1676-2584 
"primeiros habitantes," mantendo a objetividade desta explicação após a visita ao memorial ao estabelecer relação direta e sem comentários em relação à presença dos nomes nos totens, ou seja, considera que estão lá porque são pioneiros. Verificamos em Lucas, Isabel, Paulo e Carlos ${ }^{4}$ o mesmo posicionamento, além de que todos não distinguem a fonte de tal ação (construir totens e colocar nomes) e acabam por atribuir esta ação aos próprios pioneiros. Constatamos que entre as cinco crianças, três (Francisco, Paulo e Teomai) se diferenciaram ao relacionarem a presença dos nomes do memorial aos pioneiros de Londrina, estabelecendo relação espaço temporal. Vale ressaltar que o aluno Teomai se mostrou particularmente impressionado com a quantidade de nomes de pioneiros espalhados pelos Totens, pois para ele eram somente 6 pessoas que haviam "desbravado" a mata e "construído" Londrina na chegada da Caravana.

Entre as perguntas que fizemos antes da ida ao Memorial uma referia-se ao conceito de Monumento. Todas as respostas se assemelharam ao associarem monumento ao conceito de história: "Monumento é uma coisa histórica da cidade", "é onde é exposto alguma coisa histórica”, é algo precioso ou história. Depois da visita ao Memorial acrescentou-se a essas definições a idéia de que Monumento é "uma homenagem a algumas pessoas, Monumento é uma estátua e que homenageia uma pessoa que foi muito importante para aquele lugar", monumento é um documento de concreto para fazer lembrar de algo.

Muitas são as dimensões das relações socioculturais que contribuem para a constituição das idéias que formam os indivíduos como a família, a mídia, a igreja, dentre elas a presença da escola como espaço de reprodução e as vezes de crítica a valores referenciais da sociedade. No entanto muitas críticas são feitas à escola quanto ao ensino de História, indicado as como cooperadoras em reforços às perspectivas reprodutivistas da realidade. Não refutando de forma radical tal posicionamento, consideramos necessário remeter também ao mundo social externo à escola, que compõe a "heterogeneidade das experiências socializadoras" segundo Lahire (2002:31), vivida pelos seres humanos que estão inseridos, ao mesmo tempo, em variados grupos sociais, acontecendo nesse processo de socialização a experiência da pluralidade do mundo que não pode ser reduzida à escola ou à família.

O que pretendemos indicar é que são variados os fatores que podem conformar a concepção prévia das crianças e que esta terá a participação da ação pedagógica escolar como elemento desestabilizador ou não, perante o que traz de outros contextos para a escola, que no caso, parece não estar atuando nesta perspectiva crítica. Mas é preciso lembrar que, no contexto de Londrina, este tipo de reconhecimento dos pioneiros é reforçado por dimensão social que corrobora este enfoque, e que tanto o professor como a criança estão neste mesmo contexto, tendo em sua constituição ações para a construção de representações sociais na perspectiva ufanista, na idealização de desbravadores, que seriam os pioneiros presente na ideologia do progresso associada à construção da identidade de Londrina e região conforme a inscrição no totem inicial da série de quinze dedicados aos pioneiros:

Eles vieram de várias partes do Brasil e do mundo. Eram homens, mulheres e crianças. Enfrentaram a lama, a poeira, as doenças, $o$ isolamento, as dificuldades. Fizeram tudo isso em nome de um sonho. E o sonho era edificar uma cidade para todos e a felicidade de cada um. 
Com o Memorial do Pioneiro Londrina rende a homenagem aos personagens da colonização da Terra Vermelha, entre 1918 e 1939.

Aqui estão os nomes e sobrenomes, tão variados entre si, quanto a composição étnica de nosso povo.

Em 2007, século XXI, verificamos, em um grupo de dez crianças situadas na faixa etária entre 9-10 anos, a permanência de representações, que dominam o contexto sociocultural destas, o que também não foi superado pelo próprio ambiente escolar.

A mudança do significado dado aos desbravadores se evidenciou na atribuição de nomes nos totens dos 'pioneiros' e na ausência destes no totem dos 'desbravadores', o que reafirmamos com Humberto Puiggari Coutinho, fundador do primeiro jornal do município, o Paraná Norte, que em obra escrita em 1959 e reeditada em 1997, ao descrever os primeiros anos do município disse que Londrina:

...não passava de uma imensidade despovoada [...]. Aqui e ali, em distancias quase regulares, encontravam-se varias abertas, como clarões, iluminando o solo exuberante de seiva virgem de onde brotariam, pela tenacidade do labor humano, os cafezais que hoje enriquecem o Estado do Paraná. (1997:15) grifo nosso.

A sutileza da mudança de significado, não escapou à análise das crianças e levou duas delas a considerarem tal fato como decorrência da "não importância dos desbravadores", ou "porque eles não colocaram" (dois) o que indica o reconhecimento da existência da opção pelos construtores; um ao reconhecer seu distanciamento do processo de produção do memorial ao considerar que "Não sei, eu acho que eles [os desbravadores] não falaram o nome"; outro atribuiu esta ausência ao número de nomes, o que nos pareceu como indicativo de que entendia os desbravadores como muitos ou dificilmente identificáveis, no entanto sinalizando a compreensão de que estes não seriam pioneiros "Acho que é porque são muitos nomes e eles não faziam parte e não foram tão importantes".

Mas o que emergiu como diferencial foi à posição de Lucas que atribuiu a ausência de nomes nos totens dos desbravadores e indígenas à História, "Porque está contando História e não nomes" esboçando a compreensão de que nomes não representam a dimensão da História, e possivelmente, porque no totem dos desbravadores havia um pequeno texto que dizia:

"Mesmo antes de 1929 quando chegou a primeira caravana da Cia de Terras Norte do Paraná, alguns homens de coragem se aventuraram na grande floresta que dominava a terra vermelha.

Foram eles os desbravadores da futura Londrina. A eles nosso respeito e admiração."

A dimensão de que a futura Londrina seria a cidade dos pioneiros aparece também na identificação das crianças de que Londrina só começou a existir com os pioneiros. A tarefa de questionar, sobre o que se vê e fazer com que as crianças pensem sobre aquilo que estão vendo, se ancoram nas idéias de Mattozzi (1998:30) sobre a possibilidade do ensino de história na escola. Para este autor, é preciso dar aos alunos tarefas de formação 
cognitiva, isto é, de formação de estruturas de pensamento e de competências para se pensar o mundo em termos históricos.

\section{Conclusão:}

Estamos tentando, com esse trabalho, descobrir como funcionam as estruturas de pensamento que a criança elabora para aprender história. Nosso objetivo metodológico visa entender como o ensino de história nas séries iniciais relaciona-se com o conhecimento social sobre a história, que advém dos diversos campos sociais, contrapõe-se, associa-se ou provoca enfrentamentos na difícil tarefa de construir meios para o desenvolvimento do pensamento histórico de crianças. Nesse sentido o trabalho com os monumentos históricos nos proporcionou discutir a história da cidade e como os sujeitos foram se tornando personagens da história do lugar.

Segundo Ivo Mattozi(1998:40) ao trabalhar com histórias locais o professor possibilita ao aluno possivelmente entender:

$$
\begin{array}{r}
\text { a importância da dimensão local na construção do conhecimento } \\
\text { do passado e que há fenômenos que devem ser analisados numa pequena } \\
\text { escala; } \\
\text { a relação entre os fatos de dimensão local e os de dimensão nacional, } \\
\text { continental ou mundial; } \\
\text { a curiosidade e o respeito pelas histórias locais do outro; } \\
\text { o respeito pelo patrimônio que testemunha o passado local; } \\
\text { os termos das questões relativas à administração e gestão do } \\
\text { território em que vivem; } \\
\text { a função e o valor das instituições incumbidas da conservação do } \\
\text { patrimônio e do estudo do passado; } \\
\text { a utilização pública das histórias locais. }
\end{array}
$$

O aprofundamento das capacidades das crianças em entender como se forma a história do local e as representações construídas através dos patrimônios e monumentos nos levam a pensar no cotidiano das cidades e na necessidade do ensino de história nas séries iniciais ensinar a ler o mundo que rodeia a criança. Só o entendimento de como este lugar onde vive foi construído pode levar o aluno a compreender como se constituem as questões que envolvem o conhecimento histórico.

Nesse sentido desenvolvemos a atividade com o Memorial do Pioneiro com a intenção de estabelecer um dialogo entre a história e a memória na perspectiva de conduzir os alunos na leitura da história da cidade.

A luta pela memória que prevalecerá na cidade leva a um processo de confrontação com a produção do conhecimento histórico sobre o local, nesse sentido, o papel da escola é muito importante na ressignificação dos espaços públicos pela demonstração dos seus significados históricos e dos papeis desempenhados pelos sujeitos na construção dos monumentos. É preciso que o ensino de história consiga estabelecer um elo de ligação entre o que se ensina na escola e os saberes que circundam o meio onde vive este aluno no presente vivido. Como afirma Riccouer citado por Fink (2008:159)

Por um lado, o presente histórico é, em cada época, o termo final de uma história realizada cumprida, um fato consumado e fim da 
história. Por outro lado, em cada época também, o presente é- pelo menos pode se tornar a força inaugural de uma história ainda por vir. (Riccouer, 1985:345)

Este é o sentido que pensamos em atribuir para o ensino de história inaugurar a cada presente uma história que ainda está por vir.

\section{Notas:}

1 Professoras pesquisadoras do Programa de Mestrado em Educação da Universidade Estadual de Londrina linha de pesquisa História Perspectivas Filosóficas, Históricas e Políticas da Educação, núcleo História e ensino de história.

2 Segundo informações da Diretoria de Patrimônio foi um consenso administrativo atribuir a primeira década o conceito de Pioneiro visto as dimensões do local onde seria construído o Memorial.

O cadastro criado pelo Museu Padre Carlos Weiss foi instituído no ano de 1994 com o objetivo segundo informações da diretoria do Museu para que fosse possível conhecer quem foram os pioneiros. Este cadastro é composto de uma ficha que pode ser preenchida por parentes e descendentes daqueles que já morreram ou estão impossibilitados. Para o cadastro do Museu não é necessário ter chegado neste período.

3 Concha Acústica é como é conhecida a uma Praça no centro de Londrina inaugurada em 1957 em homenagem ao trabalhador. O nome Concha é dado por conta de uma enorme concha situada em um palco construído na praça. È um espaço que sempre reuniu eventos culturais, manifestações políticas e completou 50 anos no dia $1^{\circ}$ de maio.

$4 \mathrm{O}$ nome das crianças apresentados neste artigo são fictícios.

5 É corrente sobre a história de Londrina que a colonização inicia-se com a chegada de uma Caravana de colonizadores que vieram à região comprar terras. "No dia 21 de agosto de 1929, chegava a Região norte do Paraná a primeira caravana da Cia de Terras Norte do Paraná com 12 integrantes, chefiada por George Craig Smith, filho de pai inglês e mãe paulista, abrindo a primeira clareira onde mais tarde seria a cidade de Londrina (Jornal de Londrina, 21/08/2007

6 Há um Totem dedicado aos indígenas que será analisado posteriormente no encaminhamento do projeto. 


\section{Referências bibliográficas}

ARIAS NETO, José Miguel. O Eldorado: representações da política em Londrina 19301975. Londrina: Editora UEL, 1998.

ARRUDA, Gilmar. Monumentos, Semióforos e Natureza nas Fronteiras. In: Natureza, Fronteiras e Territórios. ARRUDA, Gilmar (org.).Londrina: Eduel, 2005.

CARRETERO, Mario. Construir e Ensinar as Ciências sociais e a História. Porto Alegre: Artes Médicas, 1997.

CHAUÍ, Marilena. Brasil: mito fundador e sociedade autoritária. São Paulo: Fundação Perseu Abramo, 2001.

COOPER Hilary. O pensamento histórico das crianças. In: Barca, Isabel (org) Para uma educação histórica de qualidade. Actas das IV Jornadas Internacionais de Educação Histórica. Minho: Centro de investigação em Educação.2004

COUTINHO, Humberto Puiggari. Londrina: 25 anos de sua História. Londrina: Gráfica Universal, 1997.

ELIAS, Norbert. A sociedade dos indivíduos. Rio de janeiro: Jorge Zahar Ed., 1994.

GEARY, Patrick. Memória. In: LE GOFF, Jacques; SCHMITT, Jean-Claude (coord.). Dicionário Temático do Ocidente Medieval. v.2. Bauru: EDUSC, 2006.

LAHIRE, Bernard. Homem plural: os determinantes da ação. Petrópolis: Vozes,2002.

LEE, Peter. Progressão da compreensão dos alunos em História. In: Barca, Isabel. (org). Perspectivas em Educação Histórica. Actas das primeiras Jornadas internacionais de Educação histórica. Universidade do Minho,p.13-29,2001.

LEE, Peter. "Nós Fabricamos carros e eles tinham que andar a pé": compreensão das pessoas do passado(We're making cars, and they just had to Walk':understanding people in the past). In: Barca, Isabel. Educação Histórica e Museus, Portugal: Universidade do Minho; p.9-19, 2003

MATTOZZI, Ivo. A história ensinada: educação cívica, educação social ou formação cognitiva. In: Revista O Estudo Da História, ${ }^{\mathrm{a}} 3$. Actas do Congresso O ensino de História: problemas da didáctica e do saber histórico. Braga, 1998.

NORA, Pierre. Les lieux de mémoire: "Entre mémoire e histoire _ La problématique des lieux , Paris: Galimard. 1984, vol.1 p. xix.

POLLACK, Michael. Memória e Identidade Social. In: Estudos Históricos. v.5. n 10. Rio de Janeiro: 1992, p.200-212.

RICCOEUR, P. Temps et récit. L’intrigue et lê récit historique.T. 2: La configuration dans récit de fiction. T3: Lê temps raconté. Paris: Seiu(1983-1985). Apud FINK, Nadine. As testemunhas e o ensino de história:uma abordagem didática. In: Educação em Revista.Belo Horizonte: FAE/UFMG, nº47,2008.p.159.

RUSEN, Jorn. El desarrolo de la competência narrativa em el aprendizaje histórico. In: Propuesta Educativa. Facultad Latino Americana de Ciências Sociales, Argentina;Ano4 número 7 outubro de 1992,p.27 a 37. 
SCHMIDT, Maria Auxiliadora e Braga, Tânia. A formação da consciência Histórica de alunos e professores e o cotidiano em aulas de História. In: Cadernos Cedes: Ensino de História: novos horizontes. São Paulo:Cortez, 2005.

SCHMIDT,Maria Auxiliadora e BRAGA, Tânia. O trabalho com objetos e as possibilidades de superação do seqüestro da cognição histórica: estudo de caso com crianças nas séries iniciais. In: SCHMIDT,Maria Auxiliadora e BRAGA, Tânia. (orgs) Perspectivas em Educação Histórica: Actas das VI Jornadas Internacionais de Educação Histórica. Curitiba: UFTPR,2007.

SIMAN, Lana Mara de Castro. O papel dos mediadores culturais e da ação mediadora do professor no processo de construção do conhecimento histórico pelos alunos. In: ZARTH,Paulo e outros.(orgs) Ensino de História e Educação. Ijuí: Ed. Unijui, 2004.

VYGOTSKY, L. S. A formação social da mente: o desenvolvimento dos processos psicológicos superiores. São Paulo: Martins Fontes, 1988. (Coleção Psicologia e Pedagogia)

Artigo recebido em: 29/3/2009

Aprovado para publicação em: 31/08/09 